\title{
Adding Meaningful Context to Robotics Programs (Work in Progress)
}

\section{Dr. Michele Miller, Michigan Technological University}

Dr. Michele Miller is a Professor of Mechanical Engineering at Michigan Technological University. She teaches classes on manufacturing and does research in engineering education with particular interest in hands-on ability, lifelong learning, and project-based learning.

\section{Dr. Nina Mahmoudian, Michigan Technological University}

Dr. Nina Mahmoudian is an assistant professor in the Mechanical Engineering-Engineering Mechanics Department at Michigan Technological University. She is the founding director of the Nonlinear and Autonomous Systems Laboratory (NASLab). She is a recipient of 2015 National Science Foundation CAREER award and 2015 Office of Naval Research YIP award.

\section{Dr. Mo Rastgaar, Michigan Technological University}

Mo Rastgaar received the Ph.D. degree in mechanical engineering from Virginia Polytechnic Institute and State University, Blacksburg, VA, USA, in 2008. He is currently an Associate Professor in mechanical engineering and the Director of the Human-Interactive Robotics Lab. His present research focuses on assistive robots by characterizing the agility in the human gait. Dr. Rastgaar is a recipient of 2014 NSF CAREER Award.

\section{Saeedeh Ziaeefard, Michigan Technological University}

Saeedeh Ziaeefard is a PhD student and research assistant with Nonlinear and Autonomous Systems Laboratory (NASLab) in the Department of Mechanical Engineering-Engineering Mechanics at Michigan Technological University. Her research interests include engineering education, control and navigation of autonomous underwater vehicles.

\section{Amy Joy Patterson, Michigan Technological University}

I am an undergraduate student at Michigan Technological University studying Psychology. I work as a research assistant for a number of departments at my university.

Jacob Bailey, Nonlinear Autonomous Systems Laboratory 


\section{Adding Meaningful Context to Robotics Program (Work in Progress)}

\section{Introduction}

Robots are becoming ubiquitous in our lives. They have moved beyond factories to many other environments including health care and our homes. The success of FIRST robotics shows their power to draw more young people to STEM education and careers. We believe that robots can do more to reach a wider audience including female and minority students. Robotics present a rich multi-disciplinary learning experience that touches upon STEM disciplines such as electronics, controls, fabrication, and computer programming. To broaden the representation in STEM disciplines, it is necessary to show students how they can make a difference and solve important problems. Mission-based robots show off the capabilities of robots but may not spur the imagination into coming up with ways to use robots to solve problems. Adding meaningful context may be a way to increase student interest in robotics and in STEM school subjects. As such, our project has the following research questions:

- Which robotics activities produce high levels of student engagement?

- Do the robotics activities affect student interest in STEM subjects?

- Does the addition of meaningful context to robotic hands-on activities increase the creativity of problem solutions?

We are also interested in the effects of gender and prior experiences on these questions.

\section{Summer Camp Activities}

These questions are being explored during summer educational camps for middle and high school aged students. In summer 2015, we introduced robotics activities into two week-long camps, hosted at Michigan Technological University. The Women in Engineering (WIE) camp exposes high school girls to multiple engineering disciplines. Twenty-six girls chose robotics as one of their content modules for the week. Two weeks after WIE, twenty middle school boys and girls participated in a week long Summer Youth Program (SYP) that focused solely on robotics.

The robotics activities centered on two newly developed educational robotics platforms that cost less than \$1000: an underwater glider called GUPPIE and a surface electromyography (sEMG)controlled manipulator called Neu-pulator. GUPPIE is an underwater robot that has application in monitoring and inspection of the environment, thus introducing the concept of robots as coexplorers in everyday life. Neu-pulator is a human-interactive robot that uses electrical activity of human muscles to move a manipulator. It introduces students to assistive robots, which are a class of co-robots that amplify or compensate for human capabilities. Curricular content has been developed along with the hardware platforms [1]. During WIE and SYP, students did the following:

1) Learned about robotic technology and potential application of robots.

2) Experienced the design process and learned basics of engineering design software.

3) Gained knowledge about production and assembly processes.

4) Programmed their robots using an Arduino kit (including basic electrical components, breadboard, battery and Arduino board).

5) Tested their robots. 
Testing was a highlight at the end of the week. Students deployed GUPPIE in a swimming pool and swam with it while recording water samples. Students used muscle signals to direct the Neupulator to perform different tasks.

We collected a variety of data from the WIE and SYP participants: pre and post-surveys; group interviews at the end of the week; observations; work products. Findings from the data for these first program offerings are summarized below.

\section{Description of WIE and SYP Students}

Pre-surveys showed that the WIE and SYP camps attracted much different types of students. Most obviously, the 26 WIE participants were all female and in high school. The SYP students were mostly boys ( 18 boys and 2 girls), and all were in middle school. They differed in other ways too. Only four of the 26 WIE participants had previously attended a STEM camp while 10 of the 20 of the SYP students had. The groups did report similar rates of robotics exposure: 50\% of SYP had previous robotic experience, and $46 \%$ of WIE did.

The two groups differed significantly in their hobbies. We grouped their open-ended lists of hobbies into common categories. Figure 1(a) shows that the WIE students listed many more hobbies categorized as Creative Arts (playing an instrument, drawing, making bracelets, etc.), and none listed a hobby in the category of building things (though arguably making bracelets could be categorized there). The SYP students had a higher prevalence of hobbies in the categories of technology (robotics, programming, etc.), videogames, and outdoor activities (hunting, camping, etc.). Digging deeper into videogames, the SYP students spend much more time on that than the WIE students, as shown in Figure 1(b).
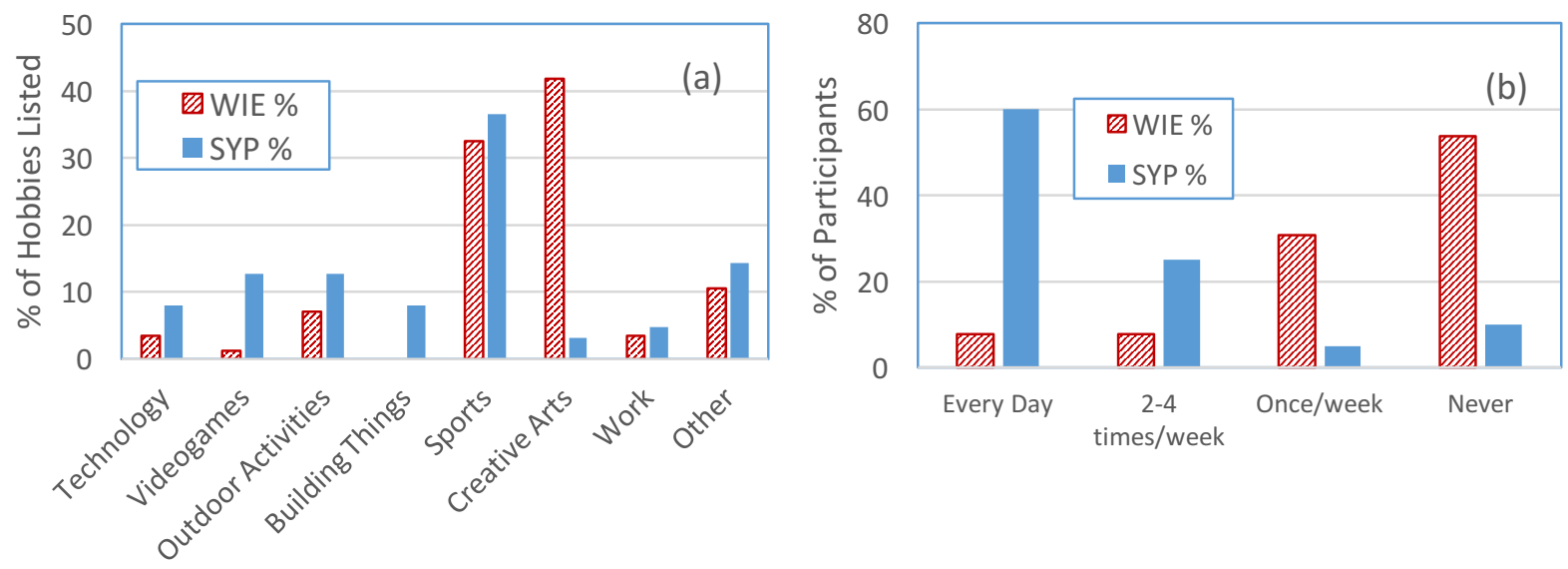

Figure 1. Comparison of (a) hobbies and (b) frequency of video game play

The two groups also differed in terms of career interest. For the WIE students the top career interests were biomedical engineering (7 students), chemical engineering (5), medicine (5), mechanical engineering (4), and environmental engineering (4). Reasons for career interest area included: "I like helping people", "I like problem solving", "I like math and science". For the SYP students, the top career interests were engineering (6 students) and mechanical engineering (5). Because these are younger students, it makes sense that many students indicated "engineering" rather than a specific branch. The reasons for their choices also included liking math and science and helping people; however, there were many responses along the lines of "because I love it so much." 
In both the pre and post surveys, students rated their level of interest in seven STEM subjects. Figure 2 compares the median WIE and SYP responses in the pre-survey. Note that both groups have high levels of interest in designing/making things, science, and math. The SYP students have higher levels of interest in robotics, using computers, and computer programming.

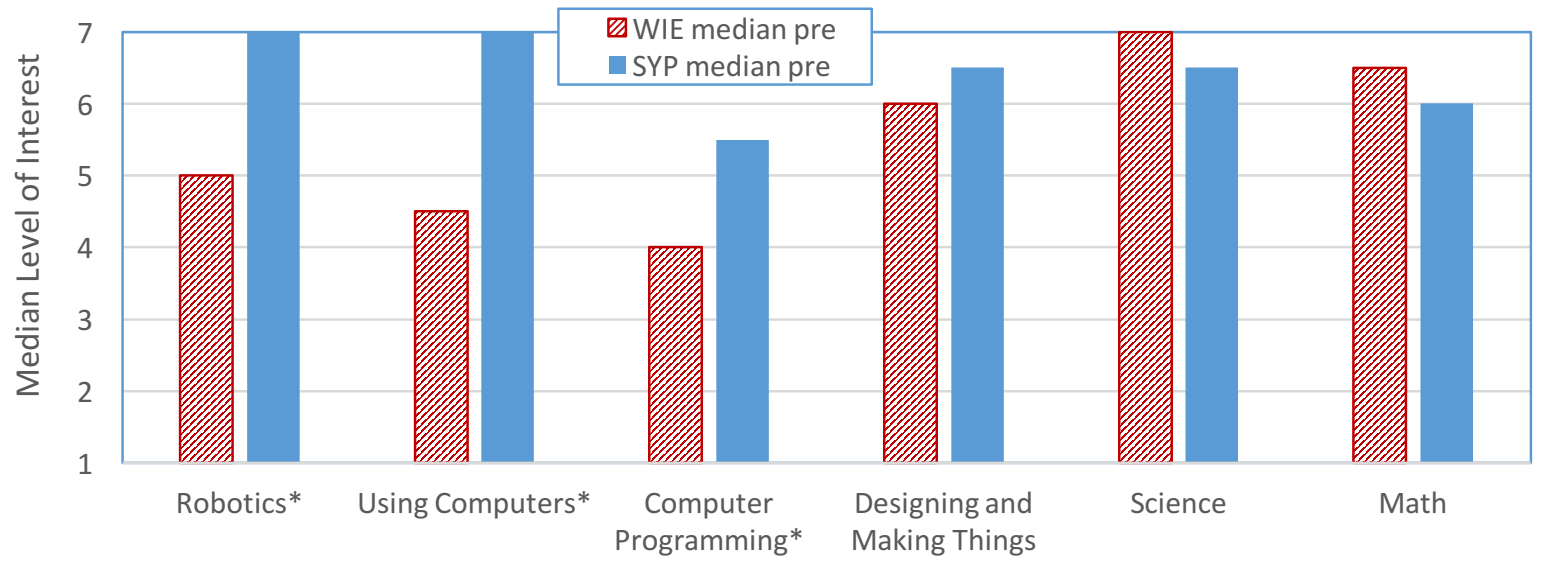

Figure 2. Comparison of interests, rated on a 7-point scale from 1 (not at all interested) to 7 (very interested); * indicates significant difference according to Mann-Whitney $\mathrm{U}$ test $(p<0.05)$

Besides interest, students also rated their comfort with computers on a scale of 1 to 7 (very comfortable). For the WIE students and SYP students, the medians were 5 and 6 , respectively. Nine of 26 WIE students and eight of 20 SYP students had previously done some programming (with a language like Java or $\mathrm{C}$ ). We asked those students how much they like programming; the median responses on a scale of 1-7 were 4 for the WIE students and 6 for the SYP students. These ratings about comfort and programming align with the interests in Figure 2.

The differences between these groups is important in that it says something about who decides to attend a robotics camp. The SYP students chose to attend a week-long camp. Their hobbies and interests are consistent with that choice. The WIE students, with their high interest in math and science, chose to attend a week-long engineering camp; however, they did not necessarily have a strong interest in robotics and computers.

\section{Impact of Robotics Activities}

We compared pre to post survey responses to determine the impact of the camps on student interests and attitudes about robots. Referring to the topics in Figure 2, the median level of interest of the WIE students rose from pre-survey to post-survey for Robotics, Using Computers, Computer Programming, and Math. The level of interest decreased for Designing/Making Things and Science. However, due to the small sample size, none of these changes was statistically significant except for the decrease in interest in science. This is an unexpected finding that we will explore further in subsequent camps. For the SYP students, interest in computer programming and math increased while interest in science decreased. However, none of these changes was statistically significant.

To assess the impact of the program on students' perceptions of the value of robots, the pre and post surveys asked students to "List things that you think a robot is most useful for." We grouped student responses into three categories: capability, research/exploration, helping people. Some responses spanned multiple categories. For example, "exploration and doing the jobs that 
humans can't" would fit in all three categories. For the WIE students Figure 3 shows the pre and post survey results for the two sets of students. The pre and post distributions of uses is similar from pre to post, with the portion of research/exploration uses going up slightly.

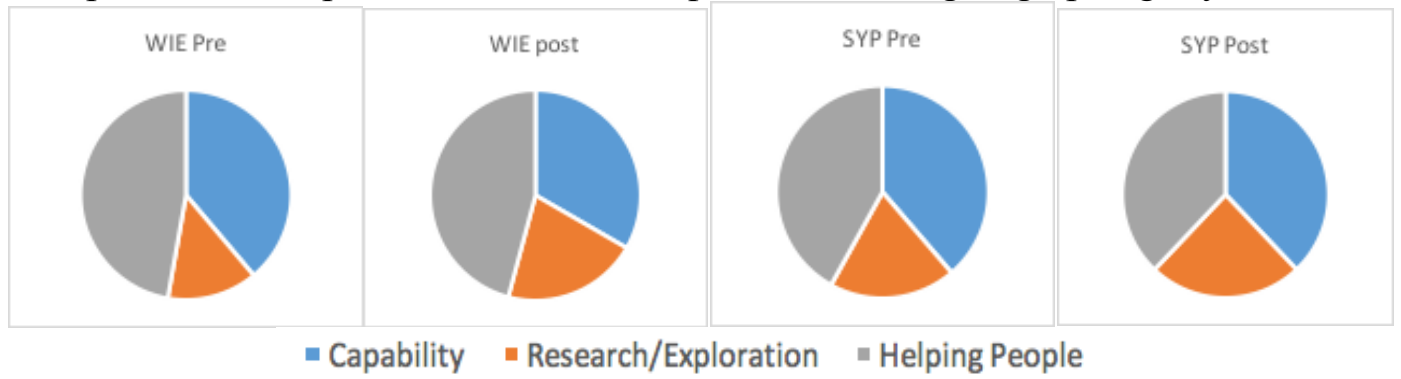

Figure 3. Categorization of responses to: "List things that you think a robot is most useful for"

\section{Student Engagement}

The post-survey asked students what they liked most about the program and why. Responses were then categorized. Table 1 summarizes the responses for both groups. For both groups, building was the favorite activity, followed by programming. Fun and enjoyment was a common explanation for why they liked an activity. Hands-on was also a common explanation.

Challenge was mentioned by two SYP students. For one student in SYP, having a background in a topic made it a favorite while for two WIE students, the lack of familiarity (hadn't seen it or done it before) made it a favorite.

Table 1. Favorite parts of robotics program

\begin{tabular}{|l|c|c|}
\hline Activity & Number of Mentions, WIE & Number of Mentions, SYP \\
\hline Building & 7 & 10 \\
\hline Programming & 4 & 5 \\
\hline Using Arduino boards & 3 & 2 \\
\hline Wiring & & 1 \\
\hline 3D modeling and 3D printing & 2 & 1 \\
\hline Using robot & 1 & 1 \\
\hline Creating a presentation & 1 & \\
\hline
\end{tabular}

Table 2. WIE reasons for favorites

\begin{tabular}{|l|c|}
\hline Reason & Number \\
\hline Fun and enjoyment & 3 \\
\hline Hadn't done it or seen it before & 3 \\
\hline Hands-on & 2 \\
\hline Sense of accomplishment & 1 \\
\hline Applied to real-life & 1 \\
\hline
\end{tabular}

Table 3. SYP reasons for favorites

\begin{tabular}{|l|c|}
\hline Reason & Number \\
\hline Fun & 6 \\
\hline Challenging & 2 \\
\hline Interesting/exciting & 2 \\
\hline Had background with it & 1 \\
\hline Can see a future use & 1 \\
\hline Hands-on & 1 \\
\hline
\end{tabular}

Tables 4-7 summarize the results for the companion question about least favorite part and why. For the WIE students, computer activities and programming rose to the top of the list.

Programming was also least favorite for four SYP students. Though building was the favorite activity for most SYP students, four cited some aspect of building as least favorite, such as "when someone in my group fried something." In terms of reasons, insufficient time for the activities was the top reason for the WIE students. For both groups, being difficult or hard to understand was a reason for least favorite status. Group interviews at the end of the week 
reinforced these findings. For example, several students said they did not like programming because they did not have a background in it, and it was too difficult. Addressing that lack of knowledge will be a way to increase engagement in future camps.

Table 4. WIE least favorite parts

\begin{tabular}{|l|c|}
\hline Activity & Number of Mentions \\
\hline 3D modeling & 4 \\
\hline Programming & 3 \\
\hline 3D printing & 2 \\
\hline Final presentation & 2 \\
\hline Arduino & 1 \\
\hline
\end{tabular}

Table 6. SYP least favorite parts

\begin{tabular}{|l|c|}
\hline Activity & Number of Mentions \\
\hline Programming & 4 \\
\hline Aspects of building & 4 \\
\hline 3D modeling & 1 \\
\hline
\end{tabular}

Table 5. WIE reasons for least favorites

\begin{tabular}{|l|c|}
\hline Reasons & Number of Mentions \\
\hline Not enough time & 6 \\
\hline Complicated/difficult & 3 \\
\hline Lack of experience & 2 \\
\hline Already knew how & 2 \\
\hline Lack of ability & 1 \\
\hline
\end{tabular}

Table 7. SYP reasons for least favorites

\begin{tabular}{|l|c|}
\hline Reason & Number of Mentions \\
\hline Confusing/didn't understand & 3 \\
\hline Difficult & 2 \\
\hline Boring & 1 \\
\hline
\end{tabular}

\section{Conclusions and Future Work}

We plan to offer the robotics program to more students in the coming summers. In this first summer of camps and data collection, we learned about the types of students that robotics programs attract. Most already have very high interest in STEM subjects. This coming summer, we will recruit more students with no previous robotics experience and lower STEM interest. Then, it will be possible to measure whether the program has a positive impact on STEM interest, thus addressing one of our research questions.

In terms of the research question about engagement, building was the most engaging activity for most students last summer. Adjustments will be made to the programming activities to increase student comfort and confidence. When less experienced students participate this summer, we will learn more about how student characteristics affect engagement in the various activities.

Ideas about what robots could do did not change substantially from pre to post survey. That could be because many students had previous robot experience. Also, it was our intention to evaluate work products to gauge whether the exposure to a breadth of robotics applications would lead to more creative solutions. We learned that last summer's program did not give students sufficient time to modify their creations or explore different approaches. That will be addressed in future offerings.

\section{Acknowledgment}

This work is supported by National Science Foundation under grant number 1426989.

\section{References}

[1] Ziaeefard, S., N. Mahmoudian, M. Rastgaar and M. Miller, "Engaging Students in STEM Learning through CoRobotic Hands-On Activities (Evaluation)," Proc. ASEE Annual Conf. and Exp., 2016. 